\title{
Homeschooling no contexto político brasileiro e os seus impactos para a Educação enquanto Direito Social
}

\author{
Homeschooling in the Brazilian political context and its impacts on \\ Education while Social Law
}

\begin{abstract}
Marta Rosani Taras Vaz
Doutora e Mestre em Educação pela Universidade Estadual de Ponta Grossa (UEPG), licenciada em Pedagogia pela Universidade Estadual do Centro-Oeste (UNICENTRO). Professora do departamento de Pedagogia da Universidade Estadual do Centro Oeste (UNICENTRO).

Irati-PR, Brasil. martarosanni@hotmail.com
\end{abstract}

Ana Eduarda Taras Vaz Licenciada em Pedagogia pela Universidade Estadual de Ponta Grossa (UEPG). Especialista em Educação Especial Inclusiva pela Faculdade São Brás (UNINA). Ivaí-PR, Brasil. anadudavaz@hotmail.com

Resumo: Esse artigo tem o objetivo de refletir sobre o movimento homeschooling no contexto educacional brasileiro, problematizando as contradições da educação pública ofertada pelo Estado e da perspectiva liberal da educação domiciliar, mediante os impactos dessa perspectiva educacional na Educação enquanto Direito Social. Além de situar as origens do tema em questão, procuraremos expor ao leitor o aparecimento dos projetos na Câmara Federal do Brasil, apresentando alguns aspectos relevantes dos projetos de lei para discussão. Por fim, a partir da perspectiva teórica adotada neste trabalho e com base no objeto investigado, consideramos a necessidade da construção de uma sociedade que possibilite uma educação para além das estruturas vigentes e, portanto, uma educação que, efetivamente, seja um direito humano e social.

Palavras-chave: Homeschooling. Educação Domiciliar. Direito Social. Projetos de Lei.

Abstract: This article has the objective in reflect on movement homeschooling in the Brazilian educational context, problematizing the contradictions of public education offered by the State and the liberal perspective of home education, through the impacts of this educational perspective on Education while social law. In addition to locating the origins of the topic in question, we will try to expose the reader to the appearance of projects in the Federal Chamber of Brazil, presenting some relevant aspects of the bills for discussion. Finally, from the theoretical perspective adopted in this work and based on the object investigated, we consider the need to build a society that allows education beyond the current structures and, therefore, an education that is effectively a human and social law.

Keywords: Homeschooling. Home Education. Social Law. Law Projects. 


\section{Introdução}

O termo "bomeschooling" tem origem norte-americana e remete às propostas que sugerem que o processo educativo escolar seja substituído pelo ensino domiciliar. Este processo pode acontecer tanto pela oferta de ensino articulado totalmente pelas famílias, quanto pela contratação de profissionais ou empresas que ofertam aulas particulares.

De modo geral, entendemos que o debate aqui exposto, compreende a prática do homeschooling como a substituição total da frequência escolar pelo ensino doméstico - seja ele ofertado apenas pela família ou pela contratação de profissionais ou empresas. Alguns termos que aparecem no âmbito desta discussão como "educação domiciliar", "ensino em casa" ou a própria sugestão de tradução de homeschooling (escola em casa), serão tratados, neste artigo, com o mesmo sentido.

Esse artigo objetiva refletir sobre o homeschooling no contexto educacional brasileiro, problematizando as contradições da educação pública ofertada pelo Estado e da perspectiva liberal da educação domiciliar, mediante os impactos dessa perspectiva educacional na Educação enquanto Direito Social. Para tanto, no primeiro momento, situamos as origens do tema em questão, apresentando algumas de suas definições. No segundo momento, organizamos e indicamos o aparecimento de Projetos de Lei na Câmara Federal do Brasil. Por fim, refletimos sobre as contradições do objeto investigado e defendemos a necessidade da construção de uma sociedade que possibilite uma educação para além das estruturas vigentes e, portanto, uma educação que, efetivamente, seja um direito humano e social.

\section{Origens e definições da educação domiciliar}

À procura de definições acerca dos termos utilizados para tratar da educação em casa, encontramos autores como Kotsubo (2018) que trata da educação domiciliar como um método de ensino, segundo ele:

[...] Homeschooling, Home Education, Ensino Doméstico, Ensino Domiciliar, Educação Domiciliar ou Educação Não Formal, o qual consiste em um método educacional onde todo o conteúdo pedagógico é ministrado diretamente ao aluno pelos seus próprios pais ou responsáveis no âmbito do seu lar, em contraposição ao método tradicional. (KOTSUBO, 2018, p. 58). 
Por sua vez, Andrade (2014) defende que o termo bomeschooling trata não apenas de uma proposta ou método, mas de um movimento social mundial crescente que possui aspirações legítimas e que, de acordo, com o autor:

O centro irradiador do Movimento pela Educação Familiar Desescolarizada são os Estados Unidos da América, ao lado de alguns países europeus. A maior parte da literatura disponível provém de autores de nacionalidade estadunidense, ou é encontrada na língua inglesa. [...] durante os anos 1960 e 1970, um movimento homeschooling teria se levantado para rejeitar a inovação moderna da educação obrigatória, de modo a promover o retorno à abordagem onde os pais são responsáveis pela educação de seus filhos. (ANDRADE, 2014, p. 29).

À vista disso, podemos compreender que o movimento, proposta ou método de Homeschooling se apresenta, de certo modo, como uma negação do processo de educação que acontece dentro dos espaços escolares. Essa afirmativa também decorre do fato de que a maior parte dos argumentos trazidos pelos defensores da educação em casa vem acompanhada de críticas ao modelo escolar de educação.

Segundo a Associação Nacional de Educação Domiciliar (ANED), ao justificar a opção de educação domiciliar defende que:

A maioria dos pais retira os filhos da escola pelo desejo de oferecer aos filhos uma educação personalizada que possa explorar o potencial, os dons e os talentos de cada criança ou adolescente. Essa personalização costuma revelar-se tão eficaz que 2 horas de atividades por dia equivalem a mais de 5 horas na escola. (ANED, 2019).

No nosso entendimento, os defensores da proposta de educação domiciliar não possuem um discurso bem definido sobre seus objetivos e sua justificativa, contudo decorrem da negação do processo educacional escolar.

Segundo a ANED, uma das vantagens da educação domiciliar é o

Número reduzido de alunos em relação à escola; desenvolvimento de forma personalizada do potencial, dons e talentos de cada aluno; poder ensinar conforme o ritmo e o estilo de aprendizado do aluno; possibilidade de fazer a integração entre conhecimentos de áreas diversas; trabalhar num ambiente seguro, com liberdade para acertar e errar e ter maior tempo de convivência com os filhos. (ANED, 2019).

Acerca da concepção de educação domiciliar como um movimento social, de acordo com Vasconcelos (2017, p. 126), os adeptos “[...] ganham popularidade no início de 1980, especialmente 
nos Estados Unidos da América, e espalham-se pelos continentes, havendo registros, nas décadas seguintes, de experiências de educação doméstica em todo mundo". Segundo a autora, "as famílias que recorrem à educação na casa, portanto, normalmente, estariam também buscando uma formação diferente daquela oferecida pelas escolas, seja por motivos religiosos, filosóficos, contextuais, especiais ou circunstanciais". (VASCONCELOS, 2017, p. 126).

Em síntese, compreendemos que os defensores da proposta de educação domiciliar defendem que a família deve decidir irrestritamente sobre a educação de seus filhos, a partir de concepções próprias de educação, ideologia, princípios morais e éticos. A defesa pela educação domiciliar, de modo geral, ampara-se no princípio da liberdade individual - princípio fundamental do liberalismo.

\section{A educação domiciliar nos projetos de lei do congresso nacional brasileiro}

A partir de uma pesquisa realizada no site do Congresso Nacional, identificamos que há várias propostas para regulamentação da educação domiciliar no Brasil, algumas já arquivadas e outras em tramitação. Vejamos os resultados iniciais da busca:

Quadro 1 - Proposições de "Educação Domiciliar" em tramitação legislativa no Congresso Nacional - 2020

\begin{tabular}{|c|c|c|}
\hline \multicolumn{2}{|c|}{ REFINADORES } & $\begin{array}{l}\text { RESULTADOS APONTADOS PELO } \\
\text { SITE }\end{array}$ \\
\hline \multirow{4}{*}{ COLEÇÃO } & Projetos e matérias - documentos & 40 \\
\hline & Projetos e matérias - proposições & 22 \\
\hline & Diários & 6 \\
\hline & Pronunciamentos & 6 \\
\hline \multirow{3}{*}{ CASA LEGISLATIVA } & Câmara dos Deputados & 49 \\
\hline & Senado Federal & 23 \\
\hline & Congresso Nacional & 11 \\
\hline
\end{tabular}

Fonte: Site do Congresso Nacional, dados organizados pelas autoras.

Com o objetivo de nos atermos aos Projetos de Lei e às Propostas de Emenda Constitucional em relação à temática, refinamos os resultados para "Projetos e matérias proposições" - em função de que é neste item que se encontram proposições para educação domiciliar, isto é: Projetos de Lei, Propostas de Emenda Constitucional, etc.

Encontramos 22 resultados, sendo que, alguns deles tratavam de proposições de audiências para discutir o tema. Procuramos, em cada resultado, aqueles que dizem respeito às propostas de legislação e encontramos Projetos de Lei e uma Proposta de Emenda Constitucional no âmbito da Câmara dos Deputados. Organizamos os dados por número do Projeto de Lei ou Emenda 


\section{Dialogia}

VAZ, Marta Rosani Taras; VAZ, Ana Eduarda Taras. Homeschooling no contexto político brasileiro e os seus impactos para a Educação enquanto Direito Social

Constitucional, situação atual em que se encontra esse documento, autor-filiação partidária e data de apresentação da proposta.

Estes dados se encontram no quadro 2, organizados por ordem anual.

Quadro 2 - Proposições referentes ao tema Educação Domiciliar na Câmara dos Deputados em tramitação no Congresso Nacional até 2020

\begin{tabular}{|c|c|c|c|}
\hline PROPOSIÇÃO & SITUAÇÃO & AUTOR & APRESENTAÇÃO \\
\hline PL 6001/2001 & Arquivada & Ricardo Izar - PTB/SP & $19 / 12 / 2001$ \\
\hline PL 6484/2002 & $\begin{array}{lll}\text { Apensado } & \text { ao } & \text { PL } \\
6001 / 2001 & & \end{array}$ & Osório Adriano - PFL/DF & 05/04/2002 \\
\hline PL 3518/2008 & Arquivada & $\begin{array}{l}\text { Henrique Afonso - PT/AC } \\
\text { Miguel Martini - PHS/MG }\end{array}$ & 05/06/2008 \\
\hline PL 4122/2008 & $\begin{array}{l}\text { Apensado } \\
3518 / 2008\end{array} \quad$ PL & Walter Brito Neto - PRB/PB & $14 / 10 / 2008$ \\
\hline PEC 444/2009 & Arquivada & Wilson Picler - PDT/PR & $08 / 12 / 2009$ \\
\hline PL 3179/2012 & $\begin{array}{l}\text { Aguardando Parecer do } \\
\text { Relator na Comissão de } \\
\text { Educação (CE) }\end{array}$ & Lincoln Portela - PR/MG & $08 / 02 / 2012$ \\
\hline PL $3261 / 2015$ & $\begin{array}{lll}\text { Apensado } & \text { ao } & \text { PL } \\
3179 / 2012 & & \\
\end{array}$ & Eduardo Bolsonaro - PSC/SP & $08 / 10 / 2015$ \\
\hline PL 10185/2018 & $\begin{array}{lll}\text { Apensado } & \text { ao } & \text { PL } \\
3179 / 2012 & & \\
\end{array}$ & Alan Rick - DEM/AC & 09/05/2018 \\
\hline PL 2401/2019 & $\begin{array}{l}\text { Aguardando } \\
\text { Constituição de } \\
\text { Comissão Temporária } \\
\text { pela Mesa }\end{array}$ & Poder Executivo & $17 / 04 / 2019$ \\
\hline PL 3159/2019 & $\begin{array}{l}\text { Apensado } \\
3179 / 2012\end{array} \quad$ ao $\quad$ PL & Natália Bonavides - PT/RN & $28 / 05 / 2019$ \\
\hline PL 3262/2019 & $\begin{array}{l}\text { Aguardando } \\
\text { Deliberação na } \\
\text { Comissão de } \\
\text { Constituição e Justiça e } \\
\text { de Cidadania (CCJC) }\end{array}$ & $\begin{array}{l}\text { Chris Tonietto - PSL/RJ , Dr. } \\
\text { Jaziel - PL/CE , Bia Kicis - } \\
\text { PSL/DF, Caroline de Toni - } \\
\text { PSL/SC e outros }\end{array}$ & 03/06/2019 \\
\hline PL 4965/2019 & $\begin{array}{lll}\text { Apensado } & \text { ao } & \text { PL } \\
4590 / 2019 & & \\
\end{array}$ & $\begin{array}{ll}\text { Pastor } & \text { Eurico } \\
\text { PATRIOTA/PE }\end{array}$ & $11 / 09 / 2019$ \\
\hline PL 5486/2019 & $\begin{array}{l}\text { Aguardando Despacho } \\
\text { do Presidente da } \\
\text { Câmara dos Deputados }\end{array}$ & $\begin{array}{l}\text { Pastor } \quad \text { Eurico } \\
\text { PATRIOTA/PE }\end{array}$ & 10/10/2019 \\
\hline
\end{tabular}

Fonte: Site do Congresso Nacional, dados organizados pelas autoras.

Os resultados evidenciam um total de 12 Projetos de Lei e uma Proposta de Emenda Constitucional. Em se referindo às proposições no Senado, encontramos os dados contidos no quadro 3, que estão organizados conforme o número do Projeto de Lei, situação em que se 


\section{Dialogia}

VAZ, Marta Rosani Taras; VAZ, Ana Eduarda Taras. Homeschooling no contexto político brasileiro e os seus impactos para a Educação enquanto Direito Social

encontram atualmente, autor e filiação e, por último, a designação do assunto do documento.

Vejamos:

Quadro 3 - Proposições referentes ao tema da educação domiciliar no senado - em tramitação no Congresso Nacional

\begin{tabular}{|c|c|c|c|}
\hline PROPOSIÇÃO & SITUAÇÃO & AUTOR & NTO \\
\hline $\begin{array}{l}\text { Projeto de Lei do Senado n } \\
28 \text {, de } 2018\end{array}$ & $\begin{array}{l}\text { Em } \\
\text { tramitação. }\end{array}$ & $\begin{array}{l}\text { o Bezet } \\
\text { E) }\end{array}$ & $\begin{array}{l}\text { Jurídico - Di } \\
\text { processual pe }\end{array}$ \\
\hline $\begin{array}{l}\text { Projeto de Le } \\
490, \text { de } 2017\end{array}$ & tramitação & Coelho (MDB/PE) & socia \\
\hline
\end{tabular}

Fonte: Site do Congresso Nacional, dados organizados pelas autoras.

Em relação à situação atual das proposições, notamos que os dois Projetos de Lei do Senado estão em tramitação. A PEC nº. 444/2009 está arquivada, bem como outros dois Projetos de Lei referentes à Câmara dos Deputados. Existem, ainda, seis documentos 'apensados' aos outros e quatro aguardando despachos ou pareceres.

Mediante o objetivo de analisar as propostas e seus objetivos, organizamos as ementas dos Projetos de Lei da Câmara dos Deputados e do Senado de forma unificada no quadro 4, onde constam: primeira coluna - proposição (Projeto de Lei ou Emenda Constitucional + número do documento); segunda coluna - breve texto que consta no item "ementa" de cada uma das proposições. Ainda no que diz respeito ao texto contido na Ementa dos documentos, percebemos que alguns fazem apenas referência à temática, como o PL nº. 6001/2001, outros detalham o objetivo do documento como o PL nº 3518/2008 e acrescentam dados complementares e outros, ainda, como os Projetos de Lei do Senado, expõem a Ementa e uma explicação da mesma para melhor entendimento do conteúdo contido no texto da proposta.

Quadro 4 - Ementa dos projetos de lei e de emendas constitucionais referentes ao tema do "Ensino Domiciliar" em tramitação no Congresso Nacional

\begin{tabular}{|l|l|}
\hline PROPOSIÇÃO & \multicolumn{1}{c|}{ EMENTA } \\
\hline PL 6001/2001 & Dispõe sobre o ensino em casa. \\
\hline PL 6484/2002 & $\begin{array}{l}\text { Institui a educação domiciliar no sistema de ensino dos Estados, do Distrito Federal } \\
\text { e dos Municípios. }\end{array}$ \\
\hline PL 3518/2008 & $\begin{array}{l}\text { Acrescenta parágrafo único ao art. 81 da Lei no 9.394, de 20 de dezembro de 1996, } \\
\text { que institui as diretrizes e bases da educação nacional e dispõe sobre o ensino } \\
\text { domiciliar. } \\
\text { Dados Complementares: } \\
\text { Autoriza o ensino domiciliar no ensino básico. }\end{array}$ \\
\hline PL 4122/2008 & $\begin{array}{l}\text { Dispõe sobre educação domiciliar. } \\
\text { Dados Complementares: } \\
\text { Altera as Leis no 9.394, de 1996 e 8.069, de 1990. }\end{array}$ \\
\hline
\end{tabular}




\begin{tabular}{|c|c|}
\hline PEC 444/2009 & $\begin{array}{l}\text { Acrescenta o } ₫ 4^{\circ} \text { ao art. } 208 \text { da Constituição Federal. } \\
\text { Dados Complementares: } \\
\text { Dispõe sobre a regulamentação da educação domiciliar. }\end{array}$ \\
\hline PL $3179 / 2012$ & $\begin{array}{l}\text { Acrescenta parágrafo ao art. } 23 \text { da Lei no } 9.394 \text {, de 1996, de diretrizes e bases da } \\
\text { educação nacional, para dispor sobre a possibilidade de oferta domiciliar da } \\
\text { eduçação básica. }\end{array}$ \\
\hline PL $3261 / 2015$ & $\begin{array}{l}\text { Autoriza o ensino domiciliar na educação básica, formada pela educação infantil, } \\
\text { ensino fundamental e ensino médio para os menores de } 18 \text { (dezoito) anos, altera } \\
\text { dispositivos da Lei no } 9.394 \text {, de } 20 \text { de dezembro de } 1996 \text {, que estabelece as diretrizes } \\
\text { e bases da educação nacional, e da Lei no } 8.069 \text {, de } 13 \text { de julho de } 1990 \text {, que dispõe } \\
\text { sobre o Estatuto da Criança e do Adolescente e dá outras providências. }\end{array}$ \\
\hline $\begin{array}{l}\text { PL do Senado } n^{\circ} \\
490 \text {, de } 2017\end{array}$ & $\begin{array}{l}\text { Altera a Lei no } 9.394 \text {, de } 20 \text { de dezembro de } 1996 \text {, que estabelece as diretrizes e } \\
\text { bases da educação nacional, e a Lei no } 8.069 \text {, de } 13 \text { de julho de } 1990 \text {, que dispõe } \\
\text { sobre o Estatuto da Criança e do Adolescente, para prever a modalidade da } \\
\text { educação domiciliar no âmbito da educação básica. } \\
\text { Explicação da Ementa: } \\
\text { Altera a Lei de Diretrizes e Bases da Educação e o Estatuto da Criança e do } \\
\text { Adolescente para facultar aos pais ou aos responsáveis a oferta de educação } \\
\text { domiciliar ("Homeschooling") a seus filhos ou tutelados. }\end{array}$ \\
\hline $\begin{array}{l}\text { PL do Senado } n^{\circ} \\
28 \text {, de } 2018\end{array}$ & $\begin{array}{l}\text { Altera o Decreto-Lei no } 2.848 \text {, de } 7 \text { de dezembro de } 1940 \text { - Código Penal, para } \\
\text { prever que a educação domiciliar não caracteriza o crime de abandono intelectual. } \\
\text { Explicação da Ementa: } \\
\text { Altera o Código Penal para estabelecer que o crime de deixar de prover à instrução } \\
\text { primária de filho em idade escolar não ocorrerá se os pais ou responsáveis ofertarem } \\
\text { aos filhos educação domiciliar. }\end{array}$ \\
\hline PL 10185/2018 & $\begin{array}{l}\text { Altera a Lei } \mathrm{n}^{\circ} 9.394 \text {, de } 1996 \text {, de diretrizes e bases da educação nacional e a Lei n } \\
\text { 8.069, de } 1990 \text {, o Estatuto da Criança e do Adolescente, para dispor sobre a } \\
\text { possibilidade de oferta domiciliar da educação básica. }\end{array}$ \\
\hline PL 2401/2019 & $\begin{array}{l}\text { Dispõe sobre o exercício do direito à educação domiciliar, altera a Lei } \text { n }^{\circ} 8.069 \text {, de } \\
13 \text { de julho de } 1990 \text { - Estatuto da Criança e do Adolescente, e a Lei no 9.394, de } 20 \\
\text { de dezembro de 1996, que estabelece as diretrizes e bases da educação nacional. }\end{array}$ \\
\hline PL 3159/2019 & $\begin{array}{l}\text { Adiciona o } \int 6^{\circ} \text { ao art. } 5^{\circ} \text { da Lei } n^{\circ} 9.394 \text {, de } 20 \text { de dezembro de } 1996 \text { (Lei de } \\
\text { Diretrizes e Bases da Educação Nacional), para estabelecer que a educação } \\
\text { domiciliar não poderá substituir a frequência à escola. }\end{array}$ \\
\hline PL 3262/2019 & $\begin{array}{l}\text { Altera o Decreto-Lei no } 2.848 \text {, de } 7 \text { de dezembro de } 1940 \text { - Código Penal, para } \\
\text { incluir o parágrafo único no seu art. } 246 \text {, a fim de prever que a educação domiciliar } \\
\text { (homeschooling) não configura crime de abandono intelectual. }\end{array}$ \\
\hline PL 4965/2019 & $\begin{array}{l}\text { Institui o Estatuto das Famílias e a definição de entidade familiar, diretriz para a } \\
\text { educação dos filhos, e outras providências. }\end{array}$ \\
\hline PL 5486/2019 & $\begin{array}{l}\text { Institui o Estatuto das Famílias, a definição de entidade familiar, a promoção de } \\
\text { políticas públicas, assim como estabelece diretrizes para a educação formal e } \\
\text { domiciliar dos filhos. }\end{array}$ \\
\hline
\end{tabular}

Fonte: Site do Congresso Nacional, dados organizados pelas autoras.

Ao observar o quadro anterior e ler cada um dos documentos, notamos que os dois documentos que correspondem ao Senado possuem semelhança e, no texto do PL do Senado ${ }^{\circ}$ 28, de 2018, o autor Senador Fernando Bezerra Coelho (MDB/PE) sinaliza que o projeto é o mesmo do Projeto de Lei do Senado n 490, de 2017, com apenas algumas alterações, sendo ele o 
autor dos dois Projetos de Lei. O mesmo caso ocorre no PL n 4965/2019, de autoria do Deputado Pastor Eurico (PATRIOTA/PE), que redige o mesmo texto do PL n ${ }^{\circ} 4965 / 2019$, mas com algumas alterações.

Outro ponto importante a ser destacado é o PL no 3159/2019, de autoria da Deputada Natália Bonavides (PT/RN), que redige um documento contra os projetos de lei que buscam regulamentar o ensino domiciliar. No texto do Projeto de Lei no 3159/2019, a Deputada sugere que a regulamentação do homeschooling não pode substituir a frequência escolar. A autora do projeto ainda destaca que "a educação domiciliar agride o princípio da igualdade de condições para o acesso e permanência na escola, bem como a liberdade de aprender e o pluralismo de ideias e de concepções pedagógicas". (BONAVIDES, 2019). Este Projeto de Lei foi apensado ao PL n ${ }^{\circ}$ 3179/2012 do Deputado Lincoln Portela (PR/MG).

Portanto, o número total de projetos de lei referentes à educação domiciliar corresponde a 15, sendo um contra. Das 14 proposições favoráveis à regulamentação do ensino em casa, 12 são projetos de lei da Câmara dos Deputados e 2 do Senado.

Analisando o material encontrado, percebemos que os termos que mais se repetem em função do objetivo do documento são: dispõe, altera, acrescenta, institui e, algumas vezes, autoriza. Tomamos essa prescrição como objeto de análise no que diz respeito ao intuito do documento e podemos compreender da seguinte forma: seis dos documentos apresentam o assunto para "dispor sobre a educação domiciliar"; cinco documentos pretendem acrescentar, incluir ou adicionar parágrafos ou incisos em leis já existentes; seis das ementas buscam alterar documentos (entre leis e decretos), com o intuito de viabilizar o ensino em casa; e, três têm como função instituir a prática.

Para compreender o fundamento e a argumentação das proposições favoráveis à educação domiciliar analisamos cada um dos documentos e destacamos seus principais argumentos. Grande parte dos projetos trouxe mais de um argumento, outros apenas um e alguns ainda expunham muito brevemente um discurso não muito bem articulado em que pudéssemos abstrair ideias e argumentos. De forma a analisar o posicionamento ideológico contido nos projetos, agrupamos os argumentos de cada um deles, destacando os principais e os organizamos da seguinte maneira:

A: Drogas e violência (5) - Um número muito significativo de argumentos se refere a essa temática, as proposições sugerem que a escola é um lugar propício à violência, uso de drogas e ao Bulling, logo a criança sendo instruída em casa, teria mais segurança.

B: Discurso Moral (6) - Proposições que trazem em seus argumentos que a escola possui concepções filosóficas que, muitas vezes, não correspondem às da família, ou que os filhos dentro de casa estarão mais próximos ao convívio familiar, produzindo um desenvolvimento moral satisfatório, de acordo com suas próprias concepções de moralidade. 
C: Má qualidade da escola (2) - Refere-se às proposições que argumentam a má qualidade dos processos educativos que acontecem dentro da escola e alguns inclusive mencionam resultados de provas e avaliações externas como Programa Internacional de Avaliação de Estudantes (PISA) e provas do Sistema Nacional de Avaliação da Educação Básica (SAEB).

D: Direito já previsto como liberdade (4) - Argumentos que afirmam que o direito à escolha por parte dos pais já é previsto em lei e que, portanto, não deve haver impedimento por parte do Estado ao ensino domiciliar.

Neste sentido, podemos observar que os Projetos de Lei que versam sobre o homeschooling, identificados no âmbito do Congresso Nacional, estão de acordo com o movimento pela Educação Domiciliar no mundo, uma vez que apresentam justificativas que estão na contramão da defesa da instituição escolar, como direito social e universal, e vão ao encontro de perspectivas liberais, no âmbito do direito individual e privado.

4 Direito à educação e as contradições entre a escola pública e a perspectiva liberal de educação domiciliar

$\mathrm{Na}$ atualidade, o senso comum está tomado por discursos de insatisfação relacionados à educação e à pesquisa, de modo a tentar colocar em xeque o conhecimento científico, filosófico e artístico. Tais discursos advêm de posicionamentos políticos e ideológicos. Dessa forma, concordamos com Schlesener (2016, p. 39) ao afirmar que "para compreender as múltiplas relações e determinações que compõem a atual situação política [...]" precisamos conhecer "[...] as características básicas da alienação e suas novas dimensões a partir dos elementos neoliberais e pósmodernos".

No momento atual, percebemos a acentuação das desigualdades sociais, que se expressam pelo aumento do desemprego, precarização de serviços públicos, diminuição do poder de compra, dentre outros problemas políticos e econômicos. Esses fatores contribuem para a promoção de discursos de indignação e revolta, por grande parte da população. Esses discursos, muitas vezes, direcionam o "fracasso" do país à má administração do Estado e o excesso de gastos com serviços públicos e direitos sociais.

Schlesener (2016), ao tratar do pós-modernismo - que está intimamente ligado à ideologia contida nos projetos de lei a favor da educação domiciliar -, compreende que suas principais características são a negação de uma visão de mundo historicista e de totalidade e a "[...] afirmação da multiplicidade de saberes que se legitimam a partir dos interesses de mercado, a fragmentação da realidade, com a valorização do individual e do cotidiano”. (SCHLESENER, 2016, p. 41). 
Desse modo, evidenciamos o ponto de partida para muitos discursos relacionados à educação e à criação de novas políticas que valorizam ideias e posicionamentos subjetivistas em detrimento de ideias e posicionamentos construídos objetivamente pela produção científica humana e social. Como, por exemplo, o Projeto de Lei no 839/2016, que propunha "a certificação de conhecimento para professores da educação básica, em qualquer área do conhecimento, e para qualquer nível de ensino". O PL ficou popularmente conhecido como "notório saber", pois designava estes termos como certificados a professores que passariam por bancas de instituições de ensino superior.

Tais propostas ganham popularidade por estarem de acordo com uma perspectiva de que os sujeitos constroem sua própria verdade a partir de suas crenças e fundamentos morais, sem necessariamente precisar do estudo científico, como já mencionamos anteriormente, o discurso da liberdade individual de escolha.

Como explicita Oliveira e Barbosa (2017, p. 194):

A fundamentação da educação domiciliar é originária de uma vasta gama de posições antiestatistas, que passam por anarquistas, liberais, individualistas e posições religiosas fundamentalistas, entre outras. Uma das correntes teóricas que também dá suporte a essa visão de educação é o neoliberalismo.

As políticas neoliberais se fundamentam nos discursos de liberdade individual para fomentar justificativas a favor do afastamento do Estado de suas responsabilidades com os direitos sociais. Oliveira e Barbosa (2017), ao tratarem dos argumentos de defesa da educação domiciliar pelo viés neoliberal, trazem à tona a linha de raciocínio sobre o Estado:

Revela-se, então, o posicionamento dos liberais, contrários a um único sistema nacional de educação. Se as famílias são diferentes em sua moral, crença e valores, como oferecer um único tipo de ensino? Que direitos tem o Estado de promover um ensino com embasamentos distintos dos apregoados pela família? (OLIVEIRA; BARBOSA, 2017, p. 195).

Neste sentido, o argumento se apresenta como um questionamento à posição do Estado frente às liberdades individuais, às escolhas de acordo com seus próprios fundamentos morais, éticos e ideológicos. Com o objetivo de observar nos argumentos dos defensores do homeschool, em relação à ideia de que os sujeitos constroem sua própria verdade, vejamos o que diz o PL n ${ }^{\circ}$ 3262/2019, de autoria da Deputada Chris Tonietto (PSL): 
A finalidade da educação é desenvolver a sabedoria. Assim, ela deve ser ordenada, portanto, ao fim último do homem, que é a contemplação da Verdade. Dessa forma, observando tal finalidade, as famílias têm retomado as rédeas do ensino de seus filhos. [...] O ser humano não é feito para o trabalho, mas para a sabedoria, a contemplação da Verdade. (BRASIL, 2019)

Ao que parece, a Deputada Chris sugere que a educação ofertada dentro das escolas está distante do "fim último do homem que é a verdade", porém, não expõe ela, em nenhuma parte do texto, o que significa ou qual o seu conceito de verdade. Dentre as ideias expostas nos Projetos de Lei que nos chamam a atenção está, também, a defesa do Deputado Pastor Eurico (PATRIOTA), apresentada no Projeto de Lei no 4965/2019, no qual o mesmo afirma:

Diante de um contexto contemporâneo de extrema confusão e desarranjo social e familiar, faz-se necessário reafirmar o entendimento milenar de família, que é a entidade constituída a partir da união de um homem e de uma mulher, denominados respectivamente de pai e mãe, por meio de casamento ou de união estável, com ou sem a existência de filhos. (BRASIL, 2019).

De acordo com o deputado, o bomeschooling deve ser aprovado para que se afirme a autoridade da família para a educação dos filhos. Família esta que, segundo o autor do texto, deveria ser composta por um homem, uma mulher e os filhos.

Para contribuir com a discussão, apresentamos outro documento importante assinado pela Deputada professora Rosa Neide (PT). Trata-se de uma Emenda Supressiva ao inciso VII do art. 33 da Medida Provisória no 870 , de $1^{\circ}$ de janeiro de 2019, que estabelece a organização básica dos órgãos da Presidência da República e dos Ministérios. A autora do texto defende que a nova organização prevista na MP reforça as possibilidades de "desescolarização" e privatização da educação.

Dentre os argumentos da Deputada, encontram-se os seguintes:

Ao nosso juízo não é salutar sinalizar a substituição de efetivos direitos por "vouchers", educação domiciliar e outras formas de bolsas e apoios, que transferem do poder público para a esfera privada a responsabilidade pela manutenção de tais direitos. Quem tiver um pouco mais, oferece um pouco mais; quem não tiver se encarregará de oferecer "o que for possível" em termos de escolarização básica. Famílias carentes devem ser atendidas pela via da oferta de escolas dignas, com qualidade, bem equipadas, com professores bem formados e valorizados, segurança e, portanto, crescentes investimentos do poder público. (BRASIL, 2019).

Compreendemos, a partir do excerto acima, que propostas como a da regulamentação da educação domiciliar podem prejudicar aqueles que não possuem condições de oferecer ensino de 
qualidade a seus filhos. Se a escola pública possui problemas, cabe ao Estado investir mais recursos para que sejam espaços de promoção de ensino de qualidade e não “jogar” a responsabilidade de um direito social à família.

Como já enfatizamos no título desta seção, mesmo tendo em vista as limitações da educação que está sob os moldes do capitalismo e, portanto, do próprio Estado, acreditamos que há um movimento contraditório neste processo. Afinal, mesmo com interesses ideológicos e econômicos da classe dominante permeando o Estado e a educação pública, esta é um direito da classe trabalhadora: professores, funcionários, coordenadores pedagógicos, estudantes e pais de estudantes fazem parte da mesma realidade.

A educação escolar deve ser entendida como um direito humano e social, pois é a instituição social que possibilita a transmissão dos conhecimentos historicamente acumulados pela humanidade. Portanto, negar o processo educativo escolar em nome de processos educativos privados é negar para grande maioria da população, pertencente à classe trabalhadora, o acesso aos conhecimentos básicos. É negar um direito social.

Entretanto, entendemos que o processo educativo, nesta sociedade, possui uma série de fatores que fazem da escola um lugar de perpetuação da ordem vigente - tendo em vista a função da escola, conforme discute Mészáros (2008). Silva (2016) ao tratar da escola compreende que "[...] na perspectiva do capitalismo, a educação é determinada no contexto das relações de classe, concentração de poder, exploração do trabalho, extração de mais-valia e, por implicação, pelas relações de produção próprias deste sistema”. (SILVA, 2016, p. 259).

Entretanto, "a escola, como instituição, expressa as desigualdades e injustiças próprias da sociedade capitalista, mas também, o conflito de interesses das classes”. (SILVA 2016, p. 260). Logo, se a escola é composta pela classe trabalhadora, ela também acaba possibilitando as condições para disseminação dos interesses da classe, no sentido de que os sujeitos que estão presentes no espaço educativo escolar podem, de maneira coletiva, expressar seus interesses.

Certamente, não podemos nos esquecer de que o processo de internalização dos valores da classe burguesa presentes na escola, faz com que muitos indivíduos se sintam culpados por problemas que decorrem do capitalismo, como a marginalização, violência e desigualdade. Todavia, se levarmos em conta que a escola pode configurar-se como espaço onde podemos proporcionar um pensamento crítico sobre o contexto em que os sujeitos e a própria escola estão imersos, então podemos considerar que a escola possui potencialidades para andar na contramão da ordem vigente, mesmo dentro de suas limitações. 
A defesa da "desescolorização" - que é propagada pelos defensores da educação domiciliar - impulsiona a não obrigatoriedade da frequência escolar; o que pode promover, no nosso entendimento, o distanciamento das crianças da classe trabalhadora da escola, sob a justificativa, por parte de seus responsáveis, de que podem receber a educação em casa.

Consideramos que, muitas vezes, é apenas na escola que se proporciona o acesso ao conhecimento e "se não for por meio da escola, é provável que muitos fiquem limitados àquilo que os meios de comunicação de massa oferecem para satisfazer a necessidade estética desse grupo". (SILVA, 2016, p. 261).

Para grande parte da classe trabalhadora, a escola se configura como o único lugar de acesso ao conhecimento elaborado e sistematizado. Portanto, cabe a nós defendermos que não ocorra a possibilidades de se retirar o direito à educação escolar.

Ainda conforme Silva (2016):

Embora a educação contribua para a reprodução das relações de produção, no que diz respeito à formação do trabalhador e à disseminação da ideologia dominante, ainda assim, a escola e a arte são espaços de contradição e, por conseguinte, abrem espaço para a possibilidade de superação de limites impostos pelas relações produtivas próprias da sociedade capitalista. (SILVA, 2016, p. 262).

Neste sentido, mesmo que a escola cumpra as funções de internalização de valores da ideologia da classe dominante e preparação para o trabalho explorado, ainda assim, configurase contraditoriamente como um direito humano e social. Instituição onde a classe trabalhadora possui acesso ao conhecimento sistematizado, acesso à cultura e à arte, mesmo que de modo precário e limitado. Apostamos ainda que, na escola, ao se permitir o convívio social com diferentes e, ao mesmo tempo seus pares, há possibilidade de constituição de lutas coletivas, como por exemplo, a luta por uma educação de mais qualidade.

\section{Considerações finais}

Cabe ao processo educativo transmitir os conhecimentos historicamente produzidos pelo homem para outros homens. Em outras palavras, de um lado, compreendemos a educação como um processo de mediação entre os homens para transmissão do conhecimento. Por outro, também compreendemos que a educação corrobora para transmitir os valores da classe dominante e, nesta sociedade, preparar o trabalhador para o trabalho alienado.

Ao longo deste trabalho, apresentamos alguns dos fundamentos das proposições para regulamentação da educação domiciliar e apontamos que esta proposta representa o risco do 
distanciamento da classe trabalhadora do acesso ao conhecimento, pois possibilita a regulamentação da oferta de ensino fora do ambiente escolar e, portanto, fere o princípio da Educação como Direito social.

Defendemos a obrigação do Estado em prover o ensino de qualidade, por meio de uma escola pública e gratuita que permita o acesso de todos ao conhecimento científico, artístico e filosófico. Entretanto, reconhecemos o fato de que a escola estatal dissemina uma ideologia burguesa e controla, em certa medida, a classe trabalhadora. Mas, então, qual educação queremos?

Queremos uma educação que vai além da formação para o trabalho alienado desta sociedade e, portanto, rompe com a própria lógica do Estado. Trata-se de uma educação que possibilite a apropriação dos indivíduos ao gênero humano, uma educação efetivamente emancipadora. Contudo, essa perspectiva educativa deve superar as contradições da educação estatal e a educação dos antiestatistas. Ela é resultado de um processo de superação das contradições mais profundas dessa sociedade: a contradição da luta de classes.

\section{Referências}

ANED. Histórico da ED nos três poderes. Disponível em: < https://blog.fastformat.co/como-fazer-citacao-de-artigos-online-e-sites-da-internet/>. Acesso em: 14/07/2020.

ANDRADE, E. P. D. A educação familiar desescolarizada como um direito da criança e do adolescente: relevância, limites e possibilidades na ampliação do direito à educação. 2014. Tese (Doutorado em educação) - Universidade de São Paulo, São Paulo, 2014.

BRASIL. Câmara dos Deputados. Projeto de Lei $\mathbf{n}^{\circ} 3159 / 2019$. Adiciona o $\int 6^{\circ}$ ao art. $5^{\circ}$ da Lei $\mathrm{n}^{\circ}$ 9.394, de 20 de dezembro de 1996 (Lei de Diretrizes e Bases da Educação Nacional), para estabelecer que a educação domiciliar não poderá substituir a frequência à escola. Disponível em: $<$ https:/ /www.camara.leg.br/proposicoesWeb/ fichadetramitacao?idProposicao $=2205161>$ Acesso em: 14/07/2020.

BRASIL. Câmara dos Deputados. Projeto de Lei no 3262/2019. Altera o Decreto-Lei no 2.848, de 7 de dezembro de 1940 - Código Penal, para incluir o parágrafo único no seu art. 246, a fim de prever que a educação domiciliar (homeschooling) não configura crime de abandono intelectual. Disponível em: < https://www.camara.leg.br/proposicoesWeb/ fichadetramitacao?idProposicao=2206168> Acesso em: 14/07/2020. Texto original.

BRASIL. Câmara dos Deputados. Projeto de Lei no $4965 / 2019$. Institui o Estatuto das Famílias e a definição de identidade familiar, diretriz para a educação dos filhos, e outras providências. Disponível em: < https://www.camara.leg.br/proposicoesWeb/fichadetramitacao?idProposicao=2219667> Acesso em: 14/07/2020. 
KOTSUBO, O. K. Homeschooling: O desafio da educação domiciliar no Brasil frente à Constituição da República Federativa do Brasil de 1988. 2018. Dissertação (Mestrado em sistema constitucional de garantia de direitos) - Centro Universitário de Bauru, Bauru, 2018.

MÉSZÁROS, I. A educação para além do capital. 2ª ed. São Paulo: Boitempo, 2008.

OLIVEIRA, R. L. P.; BARBOSA, L. M. R. O neoliberalismo como um dos fundamentos da educação domiciliar. Campinas, Proposições, n. 2, v. 28, p. 193-212, mai./ago. 2017.

SÃO PAULO. Câmara dos Deputados. Projeto de Lei no 839/2016. Dispõe sobre o reconhecimento e titulação de "Notório Saber" para os cargos de professores no Estado de São Paulo e fixa outras providências. Disponível em: < https://www.al.sp.gov.br/propositura/?id=1000009069> Acesso em: 14/07/2020.

SCHLESENER, A. H. Marxismo e educação: limites e possibilidades do conceito de emancipação. In: SCHLESENER, A. H. MASSON, G. SUBTIL, M. J. D. (Orgs.). Marxismo[s] e educação. Ponta Grossa: Ed. UEPG, 2016.

SILVA, C. R. V. Alienação, arte e educação diante do atual estágio do capitalismo. In: SCHLESENER, A. H. MASSON, G. SUBTIL, M. J. D. (Orgs.). Marxismo[s] e educação. Ponta Grossa: Ed. UEPG, 2016.

VASCONCELOS, M. C. C. Educação na casa: perspectivas de desescolarização ou liberdade de escolha? Proposições, v. 28, n. 2. mai/ago. 2017.

Recebido em: 27 mar. 2020/ Aprovado em: 17 ago 2020

\section{Cite como}

\section{(ABNT NBR 6023:2018)}

VAZ, Marta Rosani Taras; VAZ, Ana Eduarda Taras. Homeschooling no contexto político brasileiro e os seus impactos para a Educação enquanto Direito Social. Dialogia, São Paulo, n. 35, p. 148-162, maio/ago. 2020. Disponível em: https://doi.org/10.5585/dialogia.n35.16893.

\section{American Psychological Association (APA)}

Vaz, M. R. T., \& Vaz, A. E. T. (2020, maio/ago.). Homeschooling no contexto político brasileiro e os seus impactos para a Educação enquanto Direito Social. Dialogia, São Paulo, 35, p. 148-162. https://doi.org/10.5585/dialogia.n35.16893. 